\title{
Desafios da avaliação educacional: ensino e aprendizagem como objetos de avaliação para a igualdade de resultados
}

Ocimar Munhoz Alavarse

\begin{abstract}
Professor na Faculdade de Educação da Universidade de São Paulo (Feusp), tem doutorado em Educação pela USP, foi coordenador pedagógico da Rede Municipal de Ensino de São Paulo. E-mail: ocimar@usp.br
\end{abstract}

Resumo: No artigo parte-se da densidade políticopedagógica da avaliação educacional, uma das marcas indeléveis da escola e articulada às políticas educacionais, especialmente quando constatamos a disseminação das avaliações externas. Para compreender seus desafios, considera-se, inicialmente, que há um paradoxo docente, pois os professores, avaliadores profissionais, não recebem formação para tal atividade. Destaca-se, atualmente, uma associação entre qualidade do trabalho escolar e resultados de avaliação, notadamente das avaliações externas, o que é problematizado, por um lado, pela própria conceituação de qualidade e seus nexos com a avaliação, então, abordada em sua delimitação conceitual, composição e implicações. Conclui-se com a perspectiva da avaliação, tomando o ensino e a aprendizagem como seus objetos, ser ponto de apoio para uma escolarização de sucesso para todos, com a possibilidade de diálogo entre avaliações externas e internas.

Palavras-chave: Avaliação educacional. Avaliação da aprendizagem. Avaliação externa 


\section{AvaliaÇÃo educACIONAL E SUA DENSIDADE POLÍTICO-PEDAGÓGICA}

Avaliação educacional, seguramente, é um tema que, além de se desdobrar em vários outros temas correlatos, ocupa um lugar privilegiado, explícita e implicitamente, no conjunto de aspectos referentes à educação escolar há tanto tempo quanto esta tem de existência, sobretudo se a considerarmos no âmbito da escolarização de massas, pois a consolidação da escola se fez acompanhar pari passu de práticas avaliativas de modo que a avaliação fosse se conformando como uma das marcas mais indeléveis da própria escola, sobretudo quando seus resultados são destinados à definir as trajetórias dos alunos. Esta avaliação, atualmente denominada de avaliação interna, não esteve isenta de problematizações e questionamentos, gerando uma literatura gigantesca e toda sorte de regulamentações, inclusive tendo motivado iniciativas de políticas educacionais que procuraram conformá-la em moldes alternativos, como, por exemplo, é o caso da promoção automática e até mesmo na organização do ensino em ciclos.

Sem embargo, assistimos à disseminação de políticas educacionais, no caso do Brasil há cerca de 20 anos, que trazem como um de seus traços mais salientes a adoção de práticas de avaliações externas, também denominadas avaliações de sistema ou avaliação em larga escala, que, igualmente, se veem envoltas em profundos e contundentes debates. Tudo isso, certamente, incrementando os desafios em torno da avaliação educacional.

José Paulo Paes (1985, p. 10) nos indica que "é entre a recusa e o entusiasmo que corre a estrada da compreensão crítica". Indicação que parece ser adequada para tratarmos de um tema que, sem nunca ter perdido sua componente política, ganha maior densidade nas políticas educacionais e, portanto, mais propenso a ser abordado com recusas e entusiasmos, o que pode turvar sua compreensão, ainda mais quando se procurar articulá-la com vistas à escolarização que seja marcada pelo sucesso de todos os seus alunos, o que, ainda que tangencialmente, buscamos neste artigo.

À constatação da escola como uma organização no interior da qual a avaliação é um elemento constitutivo corresponde, por extensão institucional, a noção fulcral de que o professor - o agente escolar por excelência - é aquele que avalia. E a essa prática profissional de avaliação, cujos desdobramentos foram aprofundados, entre outros autores, por Lafortune e Allal (2008), também, foram se associando procedimentos e instrumentos que progressivamente se integraram a uma representação da escola que passou a presidir e orientar 
todo o processo pedagógico - talvez como o mais importante aspecto -, isto é, a escola como instituição disciplinadora de percursos individuais sancionados pelos resultados de suas avaliações.

Assim, aquilo que à primeira vista seriam apenas meios de avaliação foi convertido em rituais/ritos de passagem. Literalmente, o arcabouço da avaliação para decidir quem "passa de ano” foi, rápida e progressivamente, revestindo-se desse caráter utilitário; útil para definir as trajetórias escolares de todos aqueles que são submetidos ao processo avaliativo; algo prático para decidir quem merecia - ou não - a chancela de garantia de domínio do conhecimento escolar considerado como derivado do esforço e dedicação às tarefas escolares, portanto, dispositivo de reconhecimento do mérito. Não à toa, avaliação e meritocracia se converteram ao longo do tempo num par indissolúvel.

No Brasil, especialmente, a constatação desse caráter seletivo e suas consequências sociais levou pesquisadores e gestores de redes de ensino a proposições que confrontaram esse modo de conduzir a avaliação por entender que este estaria impedindo a democratização da escola por alimentar a exclusão, manifesta nas taxas de repetência ou nas de abandono e evasão. Daí decorrendo, por exemplo, propostas de promoção automática ou de organização do currículo em ciclos, ainda que neste último exemplo a extensão da proposta ultrapassasse as práticas de avaliação, como exposto em Alavarse (2009), pois visavam uma apreensão mais ampla da escola, sem com isso negar a relevância das práticas avaliativas. Iniciativas de confrontação e alteração da avaliação, para um rápido quadro histórico, remontam aos anos 1910 na escola primária paulista que foi reorganizada, mesmo que efemeramente, pela Reforma Sampaio Dória em 1920, como salienta Azanha (1987, p. 28), ou ainda nas contribuições de Dante Moreira Leite (1959) ao formular o caráter que deveria ter a avaliação na escola obrigatória, chegando a uma iniciativa de grande envergadura como foi a reorganização curricular na Rede Municipal de Ensino de São Paulo no início dos anos 1990.

\section{AVALIAÇÃO EDUCACIONAL: UM PARADOXO INICIAL}

Para explorarmos os desafios da avaliação do ensino e da aprendizagem, antes de apontar algumas características e tensões dessa temática com foco no interior das escolas, é possível estabelecer um desafio primitivo, considerando que os principais sujeitos dessa avaliação sejam os professores. Trata-se do que tenho denominado, no terreno da avaliação educacional, 
como paradoxo docente, nos seguintes termos: qualquer professor é um avaliador profissional que, usualmente, não tem preparação para tanto em sua formação inicial e, quiça, continuada.

Se a atividade docente é objeto de formação explícita, e obrigatória em termos legais no Brasil, nos cursos de licenciatura, pois não se admite a figura do professor leigo, a dimensão de avaliador não recebe, praticamente, formação destacada nesses cursos, pois raros são aqueles em que se encontram elementos explícitos de formação do avaliador, como temos em Gatti et al. (2010). Constitui-se, por isso, em um paradoxo, nos termos que se encontra em Blackburn (1997, p. 287-288), quer assumamos a premissa de que esse profissional receberia a formação adequada, quer assumamos (algo muito delicado) como uma conclusão, na prática inaceitável, de que as avaliações desse avaliador estão eivadas de limitações. Essa afirmação, deve-se notar, não implica que as avaliações que fazem os professores, até onde se sabe, estejam desprovidas de alguma validade e fidedignidade; trata-se de reconhecer que encontramos em muitas oportunidades uma aparente falta de nexo ou de lógica entre seus discursos e os resultados de suas avaliações. No cotidiano escolar, encontramos evidências de que a crença socialmente difundida nas avaliações dos professores, sob análise mais rigorosa, não tem toda a sustentação. Ou ainda quando estudamos os raciocínios de professores sobre suas avaliações, pois nos são revelados como, mesmo que não completamente, impregnados de contradições em sua estrutura; contradições com os princípios, de objetividade e validade, que são anunciados.

Então, como é que nós, professores avaliamos nossos alunos? De várias maneiras; decorrentes do autodidatismo, da própria prática, de referências em experiências com nossos professores e colegas, etc., mas sem indícios de vinculação com processos mais formais e apoiados em teorizações que a área da avaliação acumulou em mais de 100 anos de existência.

Até meados dos anos 80 ainda havia alguma disciplina que tinha a avaliação como objeto de ensino, na perspectiva de contribuir nessa dimensão de avaliador, porém isso desapareceu das licenciaturas. O que restou, de certa forma, foi uma "crítica”, sociológica e filosófica, à avaliação, inclusive associando-a à opressão e à exclusão. Se essa crítica, necessária, tem a sua pertinência ao campo da avaliação, pode ter levado a equívocos e lacunas formativas, pois não é a avaliação em si mesma que oprime ou exclui, mas o processo pedagógico coadunado com uma visão da escolarização que não tem o sucesso de todos como seu objetivo principal. Reversamente, a ausência 
de atividades avaliativas bem formuladas e conduzidas pode comprometer os objetivos de uma escolarização democrática, pela incapacidade de avaliar adequadamente os alunos para definir, a posteriori, a melhores ações pedagógicas para que se tenha o aprendizado de todos.

Evidentemente, não é possível asseverar que antes a formação docente era completamente adequada no que tange à avaliação; apenas devemos considerar que, nesse quadro dinâmico, um paradoxo ganhou emergência. $A$ formação dos profissionais em educação, nos cursos de licenciatura, quando muito propicia um questionamento das práticas avaliativas, uma crítica que é necessária, mas insuficiente para a formação de um profissional que vai avaliar. Por isso considero que estamos diante de um paradoxo, que pode agregar dificuldades para o próprio debate sobre avaliação escolar no seio do professorado.

Não bastando essa lacuna em sua formação para avaliar seus alunos, nas escolas onde trabalham, os professores se veem, nos tempos correntes, diante de desafios adicionais postos pelas avaliações externas, com desdobramentos curriculares e profissionais. É um quadro difícil, inclusive para o movimento sindical por conta de várias consequências que a essas avaliações estão sendo associadas, como é o caso das bonificações.

Entretanto, a constatação desse desafio primitivo nos leva a outro. Realçar que devemos nos apoiar na avaliação para a construção de uma escola de sucesso, mas que esse objetivo, ao mesmo tempo, é um mote para incrementar processos de formação em serviço em avaliação educacional que exponham os professores à fundamentação teórica e ao preparo técnico para a realização de práticas avaliativas que sejam capazes de sustentar um projeto pedagógico inclusivo.

\section{AVALIAÇÃO EDUCACIONAL: TENSÕES E PERSPECTIVAS}

Para iniciar a abordagem da avaliação educacional propriamente dita, devemos reconhecer esse quadro de presença significativa das avaliações externas, com ressonâncias acaloradas de vários matizes. Novamente nos apoiando em José Paulo Paes, quando nos aproximamos dessas avaliações assistimos recusas e entusiasmos, o que ressalta o lugar da necessária compreensão crítica. Diante de tais avaliações, encontramos, com muita frequência, dirigentes educacionais - secretários e ministros - que se entusiasmam com elas; por exemplo, encantados com a suposta precisão que 
seus números - os resultados - teriam e a capacidade de revelar a "verdade" de suas redes e escolas. Mas há, também, um tipo de oposição às avaliações externas que as recusa completamente, como se elas fossem o sinônimo de um "mal", como se fossem intrinsecamente desprovidas de qualquer significado ou importância, como se elas não tivessem nenhuma validade e fossem desprovidas de qualquer consistência. Parece-me que essas duas posturas são, com todo o respeito, equivocadas. Uns porque querem fazer política educacional como se estivessem completamente autorizados por tais procedimentos avaliativos; outros que confundem completamente a política educacional com tais procedimentos.

Os defensores incondicionais das avaliações externas, com entusiasmo exagerado supondo que sejam instrumentos de garantia absoluta da educação de qualidade, chegam a tirar conclusões como se elas permitissem revelar quem são os “melhores” e os “piores” profissionais, daí decorrendo, por exemplo, o pagamento de bônus. Essa posição, ademais de dividir os trabalhadores da educação e os enfraquecer no movimento por suas revindicações históricas, não tem lastro estatístico, pois não temos, nos resultados das avaliações externas, a segurança estatística para discriminar "melhores" e "piores", haja vista que o erro de medida que acompanha seus resultados. Em outro extremo, encontramos considerações de que essas avaliações são o que há de pior no mundo, que não que seus instrumentos não medem nada ou que os professores seriam os únicos capazes de avaliar a aprendizagem de seus alunos; para esses, portanto, é preciso recusá-las.

Como buscar uma compreensão crítica? Sem esgotar o assunto, pondero que um primeiro elemento seria problematizar a associação entre os resultados das avaliações externas e sua capacidade de expressar a qualidade da educação escolar. Problematização que, aliás, é pertinente, também, em relação às avaliações internas, pois há professores que acreditam que a avaliação que conduzem teria essa propriedade, em termos absolutos, de informar sobre a qualidade da aprendizagem de seus alunos.

Devemos relativizar essa associação, entre resultados de avaliações e qualidade do trabalho escolar, começando por algumas demarcações. Uma delas é o próprio conceito de qualidade da educação escolar. Primeiro porque é um conceito histórico, o que significa afirmar que esse conceito é mutável no tempo e em cada momento podem coexistir vários conceitos de qualidade, dependendo dos interesses em jogo ou das perspectivas que se adotem, como encontramos em Oliveira e Araújo (2005). Portanto, não existe "uma" qualidade, muito menos uma qualidade "certa" ou "errada". 
Pode-se sustentar que a qualidade de uma coisa é definida pelas propriedades que tem ou, em outro extremo, por sua excelência, por aquilo que excede em relação a outra coisa. Por isso, em muitas circunstâncias, quando se menciona sobre a qualidade de algo, na verdade, está se referindo no que essa qualidade - de uma escola ou de um aluno, por exemplo - excede à outra. Mas, podemos nos referir, também, à qualidade de alguma coisa pela descrição do que a constitui; por exemplo, podemos abordar a qualidade da educação escolar pela exposição e análise de seus elementos intrínsecos e como foram se articulando historicamente.

Ainda, no âmbito educacional, a qualidade pode ser tomada relativamente ao processo - as atividades e seus insumos - ou, em outro extremo, ao produto seus resultados. Nesta polarização, também, pode-se vislumbrar ou ênfases ou compreensões, dado que em certas oportunidades o mais relevante pode ser o processo o elemento que concentra maior importância; em outras, é o resultado. Considerando a possibilidade de que a análise de resultados faculte a inferência dos processos dos quais provêm. Evidentemente, a expressão "em outro extremo" é empregada para demarcar oposições bastante contrastantes, para efeito de exposição, pois na prática podemos encontrar posições matizadas pela combinação ou articulação desses extremos.

Para outros, a qualidade da educação escolar vai manifestar-se no acesso, permanência e conclusão de uma determinada etapa, como destacou Azanha (1987), para quem o debate sobre a qualidade de uma escola, de um sistema educacional, tinha no acesso um de suas principais variáveis. Uma educação que se apresenta como obrigatória, como emancipatória, que não garante o acesso, para Azanha (1987.), sequer entra para o debate da qualidade. Só para ilustrar, um dado dramático no Brasil é aquele sobre nossos jovens de 15 a 17 anos que revela que só metade dessa população está no ensino médio, sendo que $30 \%$ ainda estão no ensino fundamental e $20 \%$ fora da escola, estes quase todos sem concluir o ensino fundamental ou o ensino médio. Destaco que parte desse problema deriva da avaliação praticada no interior das escolas, pois no ensino fundamental os jovens que o concluem estão fazendo-o após um período de nove a dez anos, para um ensino fundamental de oito anos, o que faz do Brasil um dos países com as menores taxas de aprovação nessa etapa obrigatória da escolarização.

Outra discussão sobre qualidade da escola, para evidenciar como esse conceito não é tão simples como querem alguns que o associam mecanicamente às proficiências estimadas nas avaliações externas, é que a qualidade pode ser 
vinculada, também, à igualdade de oportunidades, que para determinadas etapas e determinados grupos sociais ainda se coloca como um desafio candente. Atentemos que, rigorosamente, o acesso não está garantido plenamente nem mesmo no ensino fundamental, pois no Brasil já chegamos a $98 \%$, que não é $100 \%$, destacando que em nosso país qualquer percentual significa muita gente em termos absolutos, que nesse caso é da ordem de mais de 800 mil crianças.

Outro modo de abordar a questão da qualidade, e que pode parecer provocação para defensores da chamada meritocracia, é tomá-la como igualdade de resultados do processo de escolarização. Setores da própria esquerda, no plano político, no máximo chegam à defesa da igualdade de oportunidades, como manifestação de uma sociedade mais justa, mas talvez a justiça para disputar quem será o “melhor”, recoloco que o problema da diferenciação entre os alunos. Nesse caso o trabalho de Marcel Crahay (2002) é paradigmático, tendo ressonância em pesquisas como a de Ribeiro (2012), ao enfatizar que a premissa democrática da escola básica impõe um tipo de justiça baseado na finalidade essencial da escola: a aprendizagem. 0 que se sustenta nessa acepção de qualidade é a bandeira de igualdade de resultados - pelo menos de alguns resultados, como é a proficiência em leitura - ao final da permanência na escola obrigatória, quando não deveriam existir diferenças entre seus concluintes. Na realidade essa diferença existe e é “abissal”. Dados da Rede Municipal de Ensino de São Paulo, tendo como referência as proficiências estimadas pela Prova São Paulo, evidenciam esse contraste, pois encontramos alunos concluindo a $8^{\mathrm{a}}$ série com desempenho equivalente à 3a série do ensino médio privado e, simultaneamente, outros alunos com desempenho equivalente à 4 a série. Nesse exemplo, considera-se que as proficiências em leitura e em resolução de problemas seriam resultados que, além de decisivos para que haja aproveitamento dos conhecimentos escolares, não deveriam apresentar tais disparidades. Essa diferença, para quem defende a escola como uma "máquina” para encontrar os melhores, é necessária, justificável e garantia de uma escola de qualidade. Mas, para quem defende a igualdade de resultados, como critério de qualidade isso é a negação de uma escola plenamente democrática.

Até aqui, pode-se perceber como a delimitação do que seria qualidade é um processo bastante complexo. Contudo, o debate pode ganhar novos contornos quando tentamos medir a qualidade, isto é, quando exploramos sua mensurabilidade. Para tanto, podemos procurar por elementos relativos ao universo escolar que sejam “manifestações” da qualidade da educação 
escolar e, ao mesmo tempo, passíveis de uma quantificação. Podemos começar pelo currículo, pois esse tópico é admitido por muitos que se debruçam sobre a escola como vinculado à sua qualidade. Como proceder? Por exemplo, podemos indagar quais são as disciplinas que o compõem; qual é a carga horária de cada uma delas, entre outros interrogantes. As discussões atuais em torno da escola de tempo integral tem, entre seus defensores, o argumento de que o aumento da carga horária vai garantir - ou aumentar - a qualidade da escola. Essa seria uma maneira de medir a qualidade da escola expressa em seu currículo.

As condições de ensino, aí incluídas as condições de trabalho dos professores como expresso na Lei do Piso, condensam, também, uma noção de qualidade da escola. Quanto os professores recebem pela venda da sua força de trabalho e em que condições vão vendê-la? Isso seria qualidade, e mensurável. No caso das condições de ensino poderíamos focar nas condições infraestruturais das escolas como um indício de sua qualidade.

Outra coisa que é possível medir, associada à qualidade, são as taxas de matrícula, de rendimento e de transição. No caso das taxas de matrícula, devemos atentar para as taxas brutas - que exprimem o fluxo, com maior ou menor incidência de repetência - e as taxas líquidas - que evidenciam a capacidade dos sistemas de atenderem quem deveria estar na escola; as taxas de rendimento compreendem as de aprovação, reprovação e abandono; as taxas de transição abarcam as de promoção, de repetência e de evasão. Tais taxas, sem entrar no mérito das divergências sobre a capacidade de expressarem a qualidade dão uma ideia completa do fluxo escolar, englobando, também, seu alcance social, aspecto que historicamente concentrou importantes desafios no desenvolvimento da escolarização no Brasil, sobretudo até início dos anos 1990.

Para concluir essa sequência de exposição sobre a mensurabilidade da qualidade da educação, pode-se admitir a medida dos conhecimentos, das competências ou das proficiências de seus alunos, em vários anos escolares e áreas de conhecimento. Nesses casos, tem-se recorrido ao uso de provas padronizadas com o tratamento dos resultados pela Teoria da Resposta ao Item para a medição desses traços, inclusive com a elaboração de séries históricas para eventuais comparações. É nesse tópico que as atuais políticas educacionais brasileiras têm concentrado suas formulações sobre a qualidade. De um lado, como já afirmado, pela crença na precisão que essas provas teriam em medir tais atributos; de outro, pelo fato de que são justamente atributos de resultados escolares que não podem ser facilmente descartados 
como expressão pertinente do trabalho escolar. Um grande exemplo dessa associação nós encontramos no Índice de Desenvolvimento da Educação Básica (Ideb) que, embora também utilizando as taxas de aprovação, apoiase em grande medida nos resultados do Sistema de Avaliação da Educação Básica (Saeb), composto pela Prova Brasil e pela Aneb.

\section{AVALIAÇÃO EDUCACIONAL: CONCEITUAÇÃO}

Embora tenhamos realizado um conjunto de problematizações em torno da avaliação educacional, rigorosamente, não explicitamos sua conceituação. Matéria controversa, a delimitação do que se compreende por avaliação tem profundas consequências práticas. Uma consulta à literatura da área registra mais de cem conceituações do que seria avaliação, ainda que nem todas sejam excludentes, como expuseram Lukas Mujika e Santiago Etxeberría (2009) em trabalho de recenseamento que encontra paralelo em Nevo (2006).

Sem consenso entre seus formuladores, constata-se, contudo, que o conceito de avaliação tem como núcleo central para a maioria de seus teóricos, e neste particular com profunda relevância para a prática escolar a rigor, a noção de julgamento. Mais amplamente, avaliação é um processo curricular, ou seja, ela é um processo - um conjunto de elementos - e, simultaneamente, faz parte do conjunto das atividades da escola - seu currículo -, ainda que professores digam, às vezes, para seus alunos “amanhã tem avaliação", querendo dizer que amanhã vão aplicar uma prova. Reversamente, quando os alunos perguntam: “Professor, o senhor vai dar avaliação amanhã?", querem perguntar se amanhã o professor vai aplicar uma prova. Excertos que revelam uma sinonímia entre avaliação e prova, ou melhor, entre avaliação e instrumento de avaliação. Se a prova é um instrumento indispensável - e poderoso, em vários sentidos - para a coleta de informações, não pode ser confundido com a avaliação.

A avaliação se consubstancia quando nós julgamos alguma coisa, que se define como um objeto de avaliação. Esse julgamento se expressa, muitas vezes, em termos de "está bom", "é aceitável”, ou mesmo com gradações do tipo “ótimo”, “adequado”, “avançado”, etc., ou ainda em termos de escalas ordinais, como é o caso de letras ou de números. Assim, avaliação não é somente reflexão, menos ainda a intervenção na realidade. $A$ avaliação lança mão da reflexão e pode contribuir com a intervenção, mas não se confunde e não se restringe a esses aspectos, até porque seria confundir avaliação com todo o processo pedagógico. 
Para que um juízo possa ser feito sobre algum objeto, duas outras condições precisam estar satisfeitas. Que existam informações consistentes a respeito desse objet,o que pode ser, por exemplo, o domínio que um aluno tem na leitura em língua materna. Para isso, como assinalado anteriormente, podem contribuir as provas justamente por permitirem levantar tais informações. A outra condição é que existam critérios de avaliação, isto é, as referências às quais as informações levantadas serão comparadas ou contrastadas. Essa delimitação de critérios é que permitirá que se faça um juízo sobre o domínio do aluno em leitura.

É possível em alguns casos efetuar esse julgamento baseado em resultados que foram traduzidos em escalas - como no Saeb - o que pressupõe a existência anterior de um processo de medida. Ocorre, na prática, que professores transformem a contagem de acertos de um aluno numa prova em um tipo de medida cuja escala é compreendida entre 0 (zero) e o total de acertos possíveis, e esses acertos sejam posteriormente cotejados com algum critério, para, então, expressar um juízo, aventando a hipótese de que as usuais notas de 0 a 10 possam ser tomadas como expressão de julgamento ou, ainda, que sirvam como um ponto intermediário para definir, isso sim, um julgamento em termos de aprovado ou reprovado.

Do exposto, mesmo que sumariamente, a ideia de avaliação associada a julgamento ressalta os "riscos e perigos" da própria avaliação, o que de passagem nos leva a considerar que nem sempre precisamos avaliar e, em decorrência, a importância de que o levantamento de informações esteja apoiado em técnicas, instrumentos e procedimentos bem organizados e aplicados, e que os critérios sejam os mais objetivos possíveis. Tudo isso para se evitar julgamentos sem a devida consistência.

Se julgamento e levantamento de informações indubitavelmente compõem a avaliação educacional, pode-se admitir, já em sua fronteira, que a noção de encaminhamentos ou de consequências seja associada à avaliação educacional, pois na escola, sobretudo, a avaliação é desencadeada com vistas à tomada de alguma decisão, o que, pode-se admitir, lhe dá o destaque que assumiu no processo histórico de consolidação da escola.

Ampliando o escopo da caracterização conceitual da avaliação educacional, é preciso que recuperemos sua natureza processual e nesse movimento alguns de seus elementos podem ser demarcados. 0 primeiro deles é o sujeito da avaliação; que significa quem a conduz, quem decide o que será avaliado. Em torno desse elemento gravitam as definições avaliação interna e externa, 
sendo aquela marcada por um sujeito interno às escolas e externa por um ente situado, do ponto de vista da operação do processo de ensino, externamente às escolas.Poder-se-ía estabeleceruma gradação de exterioridade das avaliações, pois, partindo-se das avaliações externas, temos situações nas quais estas avaliações não são completamente externas, haja vista que podem contar com a participação, por exemplo, de professores em várias etapas de suas definições. Em situações mais típicas e extremadas, as chamadas avaliações internas têm como sujeito os professores e constituem a forma escolar mais tradicional de avaliação educacional; por seu turno, nas avaliações externas o sujeito passa a ser as instâncias administrativas como são os ministérios ou secretarias, "personificadas" em seus titulares, mas raramente por eles operadas, pois isso acabando sendo incumbência de empresas contratadas, mesmo quando existe alguma instância que teoricamente responde por isso, como é o caso do Saeb, no qual o Instituto Nacional de Estudos e Pesquisas Educacionais Anísio Teixeira (Inep) não descarta a contratação de empresas. Tal quadro nos remete para o questionamento político sobre quem efetivamente controla a avaliação, mas com uma constatação: nas avaliações externas o professor perde a proeminência de avaliador que historicamente teve, pondo em questão a legitimidade política dessas avaliações.

Outro elemento do processo avaliativo é seu quanto ao objeto da avaliação, que diz respeito ao que será avaliado. Eis aqui a fonte de problemas que encontramos em algumas avaliações externas, pois o que está explicitado como objeto é a proficiência em leitura, mas, na verdade, o que está sendo avaliando é a escola ou professor. É possível avaliar escolas e professores, no entanto, ademais de que isso deva estar explicitado, tais objetos demandariam outros instrumentos e procedimentos. Guardadas as proporções, essa “imprecisão” pode ocorrer no interior de uma sala de aula quando um professor explicita que faz avaliação cognitiva sobre determinado objeto, particularmente aqueles que teriam sido objetos de ensino, mas, no fundo, integra ao objeto de avaliação outros aspectos, tais como: comportamento do aluno, material, participação em aula, estados dos materiais escolares etc. Não se trata de negar a importância desses aspectos para a configuração do aprendizado, mas tal incorporação, aliada a restrições pelo caráter moralista e subjetivo, não permite que os resultados da avaliação favoreçam os encaminhamentos sobre aquilo que deve ser o foco principal das ações escolares: as aprendizagens visadas pelo ensino.

Temos, ainda, a finalidade da avaliação, que expressa possivelmente 0 ponto de contato do processo da avaliação propriamente dita com o projeto 
pedagógico da escola. Ao redor da finalidade surge a questão da polarização entre avaliação formativa e somativa, como sistematizaram Scriven (1967) e Perrenoud (1999) ao tratarem sobre o uso que se pretende para os juízos da avaliação. Por definição, uma avaliação é considerada formativa quando seus resultados, forçosamente, são fruto de atividades avaliativas mais frequentes e enquanto o programa esteja em andamento e são destinados a (re)orientar a ação do formador, prioritariamente, mas não exclusivamente, pois os alunos, se constituídos em sujeitos da avaliação, também poderia se beneficiar dos resultados.

Isso não retira a relevância das avaliações somativas, realizadas ao final de um programa, neste caso ensejando que sobre tal programa, em suas reedições, sejam tomadas providências para superar as lacunas e deficiências que a investigação, a partir de dos resultados de sua avaliação, tenha detectado. Neste terreno, que configura plenamente a avaliação do ensino, se construiria a capacidade de aprendizagem da escola como organização "aprendente", como ponderou Álvarez Mendes (2000).

Outra variável importante do processo avaliativo se reporta ao usuário dos resultados da avaliação. O professor, quando avalia, para quem está avaliando? Quando um governo estabelece uma avaliação externa, quem será o usuário dos resultados? Quem vai usar aqueles resultados? É a imprensa? São os trabalhadores? São os sindicatos? Isso é muitas vezes ignorado ou tratado superficialmente, desconsiderando que a delimitação do usuário implica, entre outras coisas, formas e meios adequados de divulgação dos resultados para esses usuários, além do fato de que alguns objetos podem, a priori, integrar a avaliação em função dos interesses dos usuários que, por sua vez, precisam ser conhecidos previamente.

Finalmente, temos a metodologia empregada no processo avaliativo, atinente aos procedimentos e instrumentos que serão utilizados para, por exemplo, a coleta e o tratamento das informações sobre o objeto da avaliação que devem manter coerência entre si. Entre outras características, a metodologia é responsável por um "erro de medida" - quando se usam processos de medida -, pois não há medida sem erro e o desafio é controlá-lo para que sejam atingidos níveis aceitáveis para o tipo de avaliação que está sendo conduzida, especialmente no caso das avaliações externas. Por exemplo, o emprego de provas ou grades de observação demanda que se faça, sempre que possível, pré-teste de seus itens para evitar a exposição dos avaliados a tarefas avaliativas sem consistência. Quando da impossibilidade de pré-teste, 
a divulgação dos resultados deve ser precedida de um escrutínio redobrado, para que as condições de validade e fidedignidade dos mesmos estejam satisfeitas.

Ainda que não seja um problema exclusivamente metodológico, é que com respeito a esse quesito que se pode ancorar a justificativa de que as avaliações externas, notadamente pela presença avassaladora que assumem no cenário educacional brasileira, precisam ser submetidas à meta-avaliação, ou seja, devem se tornar objeto de avaliação. Dado o problema de sua legitimidade política, as avaliações externas, inscritas na delimitação de seu sujeito e de suas finalidades, devem ser controladas e acompanhadas, no mínimo, em suas etapas discriminadas pelos aspectos técnicos. Não é razoável o quadro nacional no qual governos de todos os entes federais estejam absolutamente acima de qualquer controle. Inclusive deveríamos caminhar para a fixação de um tipo de código técnico e ético com a delimitação de um conjunto de condições para que uma avaliação fosse conduzida, aí compreendidas as etapas pré, peri e pós de sua realização, com controle de erros de medida, de viéses, de validade etc. Isso não conferiria legitimidade política, aprioristicamente, mas impediria que fossem levadas a cabo sem atender aos requisitos metodológicos essenciais.

Para ilustrar, poderíamos ter, entre os vários procedimentos de acompanhamento, um grupo de professores acompanhando a realização da avaliação, inclusive, com estatísticos independentes para o tratamento dos dados, sobretudo, pelas profundas implicações para o trabalho dos professores, o que poderia melhorá-las e, em alguns casos, não publicar seus resultados. Em outros casos o debate pode - e deve - ser feito em torno das matrizes de referência da avaliação, com a delimitação daquilo que será avaliado, com permanente diálogo com o currículo, inclusive como condição para comparabilidade de resultados.

ENSINO E APRENDIZAGEM SOB AVALIAÇÃO: CONDIÇÃO PARA O SUCESSO EDUCACIONAL

À guisa de conclusão e, também, como uma questão teórica, deve-se destacar a necessidade do diálogo entre as avaliações externas e as internas. Não se trata de tirar o professor de seu lugar de avaliador, pois o paradoxo apontado anteriormente não será resolvido por essa via. Por hipótese, esse diálogo pode estimular a formação dos professores e melhorar a avaliação, pois temos tido experiências em algumas escolas com o cotejamento de resultados dessas 
avaliações e disso podemos aventar que se avaliação externa, normalmente realizada em um único dia e mesmo que com instrumentos bem elaborados, não está isenta de limitações, sendo uma delas o fato de que se um aluno não se dispuser, no dia de sua aplicação, a realizá-la com afinco, sua proficiência será, certamente, muito baixa. No entanto, encontramos os casos de alunos que são avaliados negativamente por seus professores, mas que revelam em provas padronizadas altas proficiências. Em nossas investigações, a causa disso deriva da incorporação, ressaltamos novamente, nas sínteses avaliativas dos professores de aspectos que, mesmo sendo relevantes, não estavam explicitados como objeto de avaliação pelos professores. Isso produz uma distorção para aquilo que, no fundo, devem ser o grande alvo de avaliação: a aprendizagem e o ensino.

No que toca à aprendizagem de conteúdos estabelecidos nos currículos das escolas, uma avaliação assim enviesada não faculta, por sua vez, que cada aluno seja acompanhado ao longo de sua trajetória escolar. Acompanhamento que deve estar pautado nos aspectos centrais da justificativa de frequência à escola: as aprendizagens curriculares. Entretanto, se os resultados de avaliação não as refletem, os profissionais não terão referências para delinear ações pedagógicas compatíveis com o acompanhamento pretendido.

Sem desprezar a importância dos aspectos comportamentais dos alunos, até porque podem influenciar suas aprendizagens, o foco estando efetivamente na aprendizagem e fazendo valer a noção de avaliação formativa, o ensino desencadeado na escola, transversal e diacronicamente, deve, também, ser objeto de avaliação. Nesse terreno, ainda que as avaliações externas não possam pautar o ensino, estas devem integrar o diálogo, sobejamente destacado por Nevo (1998), por meio de suas matrizes na medida em que estas, se devidamente validadas, demarcam alguns pontos de chegada esperados para os alunos.

Igualmente, devemos considerar os resultados das avaliações externas como a possibilidade das equipes escolares possuírem um panorama mais amplo de avaliação do trabalho na Unidade Educacional ao disporem de dados de outras escolas e isso não pode ser confundida com uma simples hierarquização da escola em relação a outras. Simultaneamente, embora os resultados de avaliações externas não sejam a única medida da qualidade do trabalho escolar, o fato de que essas avaliações dispõem de escalas métricas nas quais os resultados possam ser comparados ao longo do tempo permite que cada escola seja comparada a ela mesma naquilo que os dados 
expressem.

A avaliação, apesar de à primeira vista se confundir com a escolarização, não a resume. Mas a escolarização, com seu ensino e as aprendizagens almejadas, sem as devidas fundamentação e adequação de práticas avaliativas não avançará para efetivação de práticas pedagógicas que garantam o sucesso de cada aluno. Eis um desafio da avaliação educacional. 


\section{Educational evaluation challenges: teaching and learning as evaluation subjects for equality in results}

Abstract: The article starts from the educational evaluation's politicalpedagogical density, one of the school's indelible marks and articulated with educational policies, especially when we verify how disseminated external evaluations are. To understand its challenges it is taken into account at first the existence of a teaching paradox, since the teachers -- professional evaluators -- haven't received training to perform such activity. It stands now in bold relief an association between school tasks and evaluation results, mainly from external evaluations, which are rendered problematic, on the one hand by the conception of quality itself and its nexus with evaluation, broached then in its conceptual delimitation, composition and implications. It concludes with the perspective of the evaluation as a point of support for a successfull learning process for all, making it possible a dialogue between external and internal evaluations.

Key words: Educational evaluation. Apprenticeship evaluation. External evaluation. 


\section{REFERÊNCIAS}

ALAVARSE, Ocimar Munhoz. A organização do ensino fundamental em ciclos: algumas questões. Revista Brasileira de Educação, Rio de Janeiro, v. 14, n. 40, p. 35-50, jan./abr. 2009.

ÁLVAREZ MÉNDEZ, Juan Manuel. Didáctica, currículo y evaluación: ensayos sobre cuestiones didácticas. 2. ed. Madrid: Miño y Dávila, 2000. (Educación, Crítica \& Debate).

AZANHA, José Mário Pires. Democratização do ensino: vicissitudes da idéia no ensino paulista. In: Educação: alguns escritos. São Paulo: Nacional, 1987. (Atualidades Pedagógicas, v. 135). p. 25-43.

BLACKBURN, Simon. Dicionário Oxford de filosofia. Tradução de Desidério Murcho et al. Rio de Janeiro: Jorge Zahar, 1997.

CRAHAY, Marcel. Poderá a escola ser justa e eficaz?: da igualdade das oportunidades à igualdade dos conhecimentos. Tradução de Vasco Farinha. Lisboa: Instituto Piaget, 2002. (Horizontes Pedagógicos, 92).

GATTI, Bernardete et al. Formação de professores para o ensino fundamental: instituições formadoras e seus currículos. Estudos \& Pesquisas Educacionais, São Paulo, n. 1, p. 95-138, 2010.

LAFORTUNE, Louise; ALLAL, Linda (Dir.). Jugement professionnel en évaluation: pratiques enseignantes au Quévec et à Genève. Québec: Presses de l'Université du Québec, 2008. (Éducation-Intervention, 21).

LEITE, Dante Moreira. Promoção automática e adequação do currículo ao desenvolvimento do aluno. Revista Brasileira de Estudos Pedagógicos, Rio de Janeiro, v. XXXII, n. 75, p. 189-203, jul./set. 1959.

LUKAS MUJIKA, José Francisco; SANTIAGO ETXEBERRÍA, Karlos. Evaluación educativa. 2. ed. Madrid: Alianza, 2009.

NEVO, David. Avaliação por diálogos: uma contribuição possível para 0 aprimoramento escolar. In: TIANA, Alejandro (Coord.). Anais do Seminário Internacional de Avaliação Educacional, 1 a 3 de dezembro de 1997. Tradução de John Stephen Morris. Brasília: Instituto Nacional de Estudos e Pesquisas Educacionais (Inep), 1998. p. 89-97.

NEVO, David. Evaluation in education. In: SHAW, Ian F.; GREENE, Jennifer 
C.; MARK, Malvin M. (Ed.). Handbook of evaluation: policies, programs and practices. London: Sage, 2006. p. 441-460.

OLIVEIRA, Romualdo Portela de; ARAUJO, Gilda Cardoso de. Qualidade do ensino: uma nova dimensão da luta pelo direito à educação. Revista Brasileira de Educação, São Paulo, n. 28, p. 5-23, jan./abr. 2005.

PAES, José Paulo. Gregos \& baianos: ensaios. São Paulo: Brasiliense, 1985.

PERRENOUD, Philippe. Avaliação: da excelência à regulação das aprendizagens: entre duas lógicas. Tradução de Patrícia Chittoni Ramos. Porto Alegre: Artes Médicas Sul, 1999.

RIBEIRO, Vanda Mendes. Justiça na escola e regulação institucional em redes de ensino do estado de São Paulo. 455 f. Tese (Doutorado em Educação) Faculdade de Educação da Universidade de São Paulo, São Paulo, 2012.

SÃO PAULO (Município). Secretaria Municipal de Educação. Regimento Comum das Escolas Municipais de São Paulo. São Paulo: SME, agosto 1992.

SCRIVEN, Michael. The methodology of evaluation. In: TYLER, Ralph Winfred; GAGNE, Robert; SCRIVEN, Michael. Perspectives of curriculum evaluation. Chicago, IL: Rand McNally \& Company, 1967. (AERA Monograph Series on Curriculum Evaluation). p. 39-83.

RECEBIDO: Setembro de 2013.

APROVADO: Novembro de 2013. 